Journal of Social Sciences 3 (3): 155-158, 2007

ISSN 1549-3652

(C) 2007 Science Publications

\title{
A Preliminary Study of Illumination Levels in University and Elementary Classrooms in Campina Grande, Brazil
}

\author{
${ }^{1}$ Charles I. Abramson, ${ }^{1}$ Melanie C. Page, ${ }^{1}$ Mia Zolna, ${ }^{1}$ Waylon Howard \\ ${ }^{2}$ Italo S. Aquino and ${ }^{3}$ Shakuntala Nain \\ ${ }^{1}$ Oklahoma State University, Department of Psychology, 215 North Murray, Stillwater, OK 74078, USA \\ ${ }^{2}$ Universidade Federal da Paraiba, Departamento de Entomologia, Bananeiras, 58220-000, Paraiba Brazil \\ ${ }^{3}$ Universidade Federal de Campina Grande, Departamento de Educação \\ Campina Grande 58109-970, Paraiba Brazil
}

\begin{abstract}
The purpose of our study was to provide preliminary data on light levels used in university and elementary school classrooms in Campina Grande, Brazil with the aim of providing Brazilian politicians and educators with data to support continued educational initiatives in northeast Brazil. The data were gathered at the Universidade Federal de Campina Grande (UFCG) and compared with a sample of classrooms at Oklahoma State University (OSU) in Stillwater Oklahoma. The results indicated that many seats within UFCG classrooms met or exceeded minimum standards but significant numbers did not. Moreover, compared to classrooms at OSU, UFCG classrooms are not as highly illuminated and the Brazilian elementary classrooms examined did not meet minimum illumination standards.
\end{abstract}

Keywords: Brazil, illumination, education

\section{INTRODUCTION}

Recent evidence suggests that levels of light and quality of light can significantly influence behavior. Studies have shown that poor lighting conditions lead to vision difficulties, attention deficits, nutritional deficiencies and a decline in health and mood while proper lighting conditions are known to reverse these problems and increase academic performance and productivity ${ }^{[1,2]}$.

Brightness, specifically, can have a great affect on behavior, including classroom and work performance ${ }^{[3]}$. Without adequate light, visual abilities become quickly impaired $^{[4]}$. In an early study, Gerathewohl and Taylor $^{[5]}$ reported that visibility is poorest under low illumination levels because focal vision, which is necessary for reading and writing, rapidly deteriorates as light levels decrease. In particular, studies have shown that increasing the brightness of light decreases unnecessary workload and therefore increases productivity ${ }^{[1]}$.

The purpose of our study is to provide preliminary data on light levels used in university and elementary school classrooms in Campina Grande, Brazil. The population of Campina Grande is approximately 376,000 and is located in the northeast state of Paraiba.
Paraiba is one of the poorest states of the 26 states of Brazil and is subject to long periods of drought and subsequent unemployment and extreme poverty ${ }^{[6]}$. We want to provide Brazilian politicians and educators with data that can be used to support continued educational initiatives in northeast Brazil. The data were compared with a sample of classrooms at Oklahoma State University.

\section{MATERIALS AND METHODS}

In both countries, several random classrooms were selected within two educational institutions. For the United States, the institution was Oklahoma State University (OSU) located in Stillwater Oklahoma, in Brazil the institution was the Universidade Federal de Campina Grande (UFCG). The Universidade Federal de Campina Grande has the added advantage of having an elementry school ("Ensino Fundamental") on campus. Both universities have large enrollments and carry full degree programs including those leading to a Master's and $\mathrm{PhD}$. Moreover, both universities conduct agricultural research. The Brazilan readings were taken during the first to middle part of July. The readings in the United States were taken during late July.

Corresponding Author: $\quad$ C. I. Abramson, Laboratory of Comparative Psychology and Behavioral Biology, Departments of Psychology and Zoology, 215 N. Murray, Stillwater, OK 74078 
Light measurements were taken at each seat within a classroom. Measurements were made at 3 different times during the day (during the day with lights off, during the day with lights on and during the night with lights on). At OSU, 10 university classrooms were measured and at UFCG 22 university classrooms and 6 elementary school classrooms were measured. Each classroom had seats in columns ranging from close to the windows to far away from the windows ( 5 columns per class) and rows (4 to 6 rows per classroom). Each column had 4 to 8 seats. An average light reading was calculated per column. The light meter was a factory calibrated Extech Instruments Model 407026 Heavy Duty Light Meter (Waltham, MA). The light standards were obtained from guidelines established by Illuminating Engineering Society of North America ${ }^{[7]}$. These guidelines are also used in Brazil ${ }^{[8]}$.

In addition to light measurements, data were gathered on the number of fixtures per room, location of the fixture(s) the height of the fixture(s) as measured from the floor, room dimensions, window direction, window size and the weather conditions on the date measurements were taken.

\section{RESULTS}

OSU vs. UFCG classrooms: To determine the impact of country on amount of light measured, a 2 × 5 × 2 (Country x Column $x$ Time) mixed design MANOVA was run on the light measurements. Several effects were significant (Table 1 for F's and Table 2 for means). As expected, the light measurement decreased as one moved away from the window and light measurements were greater during the day with the lights on than during the day with the lights off. Overall, the country effect showed that light readings were much greater in OSU classrooms than in UFCG classrooms $\left(\mathrm{M}_{\mathrm{UFCG}}=498.61 \mathrm{lux}\right.$ and $\mathrm{M}_{\mathrm{OSU}}=811.08$ lux). Several follow-up analyses were conducted to explore the significant interactions. First, we looked at if there was a country effect at both time points. Interestingly, when collapsing across all columns, there is no significant difference between UFCG and OSU classrooms in the day, only at night (Table 1 and 2). This pattern holds when one looks by each location, light is only greater in OSU classrooms during the day with the lights on (all significant p's $<.001$ ). For both universities at both time points, there was a significant linear trend across columns. It can be seen that as in the overall analysis, light decreases as one moves away from the window (Tables 1 and 2). It is interesting that for both universities at both time points, the difference between the location closest to the window and the one furthest away is significant (p's $<.001$ ).
UFCG Classrooms vs. UFCG Elementary School: To determine the impact of school type on amount of light measured, a 2 × 5 × 2 (School Type x Column $\times$ Time) mixed design MANOVA was run on the light measurements. The effects regarding Type are of interest and are reported here. The mean light reading was higher in the college classroom than the elementary classroom $\left(\mathrm{M}_{\text {University }}=584.02\right.$ lux and $\mathrm{M}_{\text {Elementary }}=$ 185.46 lux, $\mathrm{p}=.001)$; the Row and Row X Type effects were significant $(\mathrm{p}=.01)$ and the Time $X$ Type and the 3 -way interaction were non-significant $(p>.05)$. In a follow-up analysis, it was found that the linear effect of column was significant for the university classrooms at both time points, but not for the elementary classrooms. Thus for the elementary classrooms, sitting near the window does not increase the amount of light.

UFCG classrooms at night vs. during the day: To determine the impact of time of day on amount of light measured, a $5 \times 3$ (Column $\times$ Time) repeated measures design MANOVA was run on the light measurements. All effects were significant (p's $<.001$ ). Follow-up analyses found that there was a significant difference between light measurements at night with the lights on $\left(\mathrm{M}_{\text {night }}=214.28\right.$ lux $)$ and during the day with the lights on $\left(\mathrm{M}_{\text {day lights on }}=759.96\right.$ lux $)$ and with the lights off $\left(\mathrm{M}_{\text {day lights off }}=557.77\right.$ lux $)$. Finally, during the day, light increased as one moved closer to the windows, but at night decreased as one moved closer to the windows (all p's on follow-up analyses were significant at $<$ $.001)$.

Classroom types vs. the recommended minimum light standard: To determine if the amount of light coming from each classroom met the minimum acceptable standards, one sample t-tests were run testing the average amount of light against the minimum standard value of 300 lux. For each location, each combination of time of day and column position was tested. It was found that for UFCG classrooms, six positions had significantly less light than acceptable, seven had greater than acceptable levels and two were not significantly different from acceptable levels (range 169.32 to 955.14 lux). Inadequate lighting was found in all columns at night and in column 5 during the day with lights off. For the elementary school classrooms, all of the positions, except one were significantly less than the minimum acceptable value (range 91.35 to 243.63 lux). It was found that for OSU classrooms; one 
J. Social Sci., 3 (3): 155-158, 2007

Table 1: ANOVA results

\begin{tabular}{|c|c|c|c|c|}
\hline Outcome & & $F\left(d f_{n}, d f_{d}\right)$ & $\mathrm{p}$ & Eta-squared \\
\hline Time & & $204.56(1,36)$ & .001 & .85 \\
\hline Row & & $38.99(4,144)$ & .001 & .52 \\
\hline Country & & $6.49(1,36)$ & .015 & .15 \\
\hline Time*Row & & $5.28(4,144)$ & .001 & .14 \\
\hline Time*Country & & $65.94(4,144)$ & .001 & .65 \\
\hline Country*Row & & $2.50(4,144)$ & .04 & .06 \\
\hline Time*Row*Country & & $1.64(4,144)$ & .17 & .04 \\
\hline Country at time 1 & & $.02(4,144)$ & .89 & .00 \\
\hline Country at time 2 & & $17.12(4,144)$ & .001 & .37 \\
\hline \multicolumn{5}{|l|}{ Linear trend of location: } \\
\hline Day in United States & & $10.79(1,28)$ & .04 & .28 \\
\hline Day in Brazil & & $28.60(1,28)$ & .001 & .51 \\
\hline Night in United States & & $6.35(1,28)$ & .02 & .19 \\
\hline Night in Brazil & & $23.67(1,28)$ & .001 & .46 \\
\hline School & Row & Time & Mean & SD \\
\hline \multirow[t]{10}{*}{ United States } & 1 & Day & 1058.23 & 473.58 \\
\hline & 1 & Night & 1502.51 & 341.64 \\
\hline & 2 & Day & 616.53 & 237.84 \\
\hline & 2 & Night & 1257.78 & 216.61 \\
\hline & 3 & Day & 406.21 & 172.15 \\
\hline & 3 & Night & 1040.34 & 127.88 \\
\hline & 4 & Day & 259.61 & 119.86 \\
\hline & 4 & Night & 985.24 & 111.27 \\
\hline & 5 & Day & 188.26 & 89.55 \\
\hline & 5 & Night & 796.05 & 168.57 \\
\hline \multirow{10}{*}{ Brazil } & 1 & Day & 729.088 & 591.88 \\
\hline & 1 & Night & 820.127 & 585.06 \\
\hline & 2 & Day & 502.845 & 335.70 \\
\hline & 2 & Night & 649.048 & 317.02 \\
\hline & 3 & Day & 346.209 & 224.38 \\
\hline & 3 & Night & 576.898 & 407.40 \\
\hline & 4 & Day & 286.744 & 265.88 \\
\hline & 4 & Night & 460.043 & 231.02 \\
\hline & 5 & Day & 207.308 & 140.94 \\
\hline & 5 & Night & 407.805 & 195.46 \\
\hline
\end{tabular}

position had significantly less light than acceptable and seven had greater than acceptable levels (range 186.75 to 1502.51 lux). Inadequate lighting was found in column 5 during the day with lights off.

\section{DISCUSSION}

Our preliminary results may be the first attempt to record light levels in university and elementry school classrooms in the state of Paraiba and perhaps the entire northeast of Brazil. The results indicate that many seats within the university classroom during daylight hours meet or exceed minimum standards, although a significant number of seats do not. At night, few seats meet the minimum standards. Moreover, compared to classrooms at OSU, UFCG classrooms are not as highly illuminated generally and the elementary classrooms do not meet minimum illumination standards.

The United States authors were surprised by the perceived low level of illumination in both university and elementary school classrooms. When Brazilian university students were informally asked if classroom illumination was adequate the typically response was "Yes." Brazilian students also commented that reading was difficult at a level of illumination considered appropriate by the United States authors. This suggests that UFCG students either have adapted to lower light levels or alternatively, that the United States researchers had adapted to higher levels of illumination.

Compared to the Brazilian classrooms in the Universidade Federal de Campina Grande, those in Oklahoma State University were brighter. Illumination, however, was only greater in Oklahoma State University classrooms during the day with the lights on and during the night. In both universities, the level of illumination decreased as one moved away from the window.

A comparison of the Universidade Federal de Campina Grande classrooms with the elementry school hosted on the campus revealed higher level of illumination in the university classroom. Interesting, in the elementary classrooms surveyed, sitting near the window did not increase the amount of light. Moreover, in comparison 
with the Universidade Federal de Campina Grande classrooms, the majority of elementry classrooms failed to meet recommended minimum light standards.

In conclusion, the results suggest that in UFCG acceptable levels of illumination can be found during the day but not at night. Illumination levels in the elementry school do not meet minimum standards. We would like to note that our results should not be generalized to other universities and elementry schools. UFCG is part of the Brazilian federal university system and is a main campus. Therefore our results are not representative of satalite campi or privately funded Brazilian universities. We would also caution the reader that there are experimental design questions associated with seasonally variability, classroom maintenance schedules and degree of financial support for physical plant maintenance. It should be noted, however, that a survey of 15 schools in Campinas, São Paulo State also found that few classrooms met minimum light standards ${ }^{[9]}$.

We hope our study will stimulate others to conduct similiar research in the northeast of Brazil. With the exception of capitol cities in the northeast (Fortaleza, Recife, Salvador) northeastern cities are seldom the object of psychological studies. Data is typically gathered from such well known Brazilian cities as São Paulo, Rio de Janeiro, Brasilia and Curitiba. Conducting such studies will focus attention on much needed educational reforms and increase the importance and visibility of psychology to the Brazilian public and elected officials.

Many Brazilian psychology students do not consider psychology as a natural science, especially in the northeast and conducting such studies may be one way to generate student interest in the experimental aspects of psychology ${ }^{[10,11]}$. Light level meters are relatively inexpensive and easy to use. In addition to stimulating light level studies in schools and universities, such studies can be extented to offices, homes and public places. A study conducted on home illumination levels in the United States found that the majority of homes surveyed did not meet minumum standards especially for younger adults ${ }^{[12]}$. Such studies can also serve as a stimulus for international collaboration between Brazilian scientists and students and those in other countries. The United States National Science Foundation, for example, funds internationally based cooperative programs and such collaborations should be explored ${ }^{[13,14]}$.

\section{ACKNOWLEDGEMENTS}

This work was supported in part by a Research Experience for Undergraduates grant from the National Science Foundation (SES-0097643) to Melanie C. Page and Charles I. Abramson. Further financial support was provided by a visiting professor grant to Charles I. Abramson from the Universidade Estadual da Paraíba.

\section{REFERENCES}

1. Gifford, R., 2002. Environmental Psychology: Principles and Practice. 3rd Ed. Optimal Books, Colville, WA.

2. Ott, J.N., 1976. Influence of fluorescent lights on hyperactivity and learning disabilities. J. Learn. Disabil., 9: 417-422.

3. Lomas, C.A., D. Piggins and C.J.C. Phillips, 1998. Visual awareness. Appl. Anim. Behav. Sci., 57: 247-257.

4. Owens, D.A., 2003. Twilight vision and road safety: Seeing more than we notice but less than we think. In: Visual Perception: The influence of $H$. W. Leibowitz.(Eds. J. T. Andre, D. A. Owens and L. O. Harvey) pp. 157-180. American Psychological Association, Washington, DC.

5. Gerathewohl, S.J. and W. F. Taylor, 1953. Effect of intermittent light on the readability of printed matter under conditions of decreasing contrast. J. Exp. Psychol., 46: 278-282.

6. Weil, T., 1975. Area Handbook for Brazil. American University, Washington, DC.

7. Rea, M.S. (Ed.), 2000. IESNA Lighting Handbook, $9^{\text {th }}$ Edition. Illuminating Engineering Society of North America, New York, NY.

8. Associação Brasileira de Normas Técnicas, 1992. Illuminância de interiors (NBR 5413). ABNT, Rio de Janeiro, RJ, Brazil.

9. Kowaltowski, D.C.C.K., S.A.M.G. Pina, R.C. Ruschel, L.C. Labaki, S.R. Bertolli and F.B. Filho, 2006. Environmental comfort and school buildings: The case of Campinas, SP, Brazil. Environ. Behav., 38: 155-172

10. Morales, B.L., C.I. Abramson, S. Nain, N.A. Junior and A.B. Bartoszeck, 2005. The status of psychology as a science in northeast Brazil: Undergraduate student perceptions. Psychol. Rep., 96: 109-114.

11. Bartoszeck, A.B., C.I. Abramson, C.I. and A.J. Place, 2005. The perception of students in the south of Brazil on the status of psychology as a science. Psychol. Rep., 97: 750-756.

12. Charness, N. and K. Dijkstra, 1999. Age, luminance and print legibility in homes, offices and public places. Hum. Factors, 41: 173-193.

13. Abramson, C.I. and A.B. Bartoszeck, 2006. Improving the psychology undergraduate curriculum in developing countries: A personal note with illustrations from Brazil. J. Soc. Sci., 2: 108-112.

14. Page, M.C., C.I. Abramson, C.I. and J. Jacobs-Lawson, 2004. The National Science Foundation research experience for undergraduates program: Experiences and recommendations. Teach. Psychol., 31: 241-247. 